\title{
The implementation of an ISO 9000 quality system
}

\begin{abstract}
This paper indicates that ISO 9000 elements that relate to an organization quality system are hard to implement compared to elements that relate to operational procedures. The elements that are identified as difficult to implement and related to an organization quality system are: corrective and preventive actions, design control, management responsibility, statistical techniques, process control, document and data control and quality system. The elements that are perceived as easy to execute are: inspection and test status, packaging, preservation, and delivery, and inspection and testing. In addition, it has been found that companies that market their products in Europe, or engage in intense interaction with foreign partners, perceive a lesser degree of difficulty in practising the requirements of ISO 9000 series of standards compared to companies that do not have fair market share in Europe, or lack of foreign interactions. This argument works for companies with different ranges of paid-up capital or operating years.
\end{abstract}

Keyword: ISO 9000; Europe; International standards 